\title{
Environmental Change and Its Impacts on Lives and Livelihoods of South-Central Coastal Districts of Bangladesh
}

\author{
Md. Mahmudul Hasan ${ }^{1, ~ *, ~ R u m a ~ K h a n a m ², ~ M d . ~ I b r a h i m ~}{ }^{3}$, A. K. M. Mostafa Zaman ${ }^{4}$ \\ ${ }^{1}$ Department of Geo-Information Science and Earth Observation, Faculty of Disaster Management, Patuakhali Science and Technology \\ University, Patuakhali, Bangladesh \\ ${ }^{2}$ Department of Disaster Resilience and Engineering, Faculty of Disaster Management, Patuakhali Science and Technology University, \\ Patuakhali, Bangladesh \\ ${ }^{3}$ Faculty of Disaster Management, Patuakhali Science and Technology University, Patuakhali, Bangladesh \\ ${ }^{4}$ Department of Agronomy, Faculty of Agriculture, Patuakhali Science and Technology University, Patuakhali, Bangladesh
}

\section{Email address:}

mahmudulhasandm30@gmail.com (Md. M. Hasan)

${ }^{*}$ Corresponding author

\section{To cite this article:}

Md. Mahmudul Hasan, Ruma Khanam, Md. Ibrahim, A. K. M. Mostafa Zaman. Environmental Change and Its Impacts on Lives and Livelihoods of South-Central Coastal Districts of Bangladesh. American Journal of Biological and Environmental Statistics. Vol. 4, No. 2, 2018, pp. 42-48. doi: 10.11648/j.ajbes.20180402.11

Received: February 19, 2018; Accepted: March 5, 2018; Published: March 23, 2018

\begin{abstract}
The coastal region of Bangladesh is highly vulnerable to disasters due to its geographical location and cover about $20 \%$ of total land area and over $30 \%$ of the cultivated lands of the country. The coastal ecosystem of Bangladesh encompasses a highly functional and structurally diverse ecology e.g. the world's largest mangroves forest (the Sundarbans), dunes, wetlands, beaches, and coral reefs. It provides a wide range of goods and services to the people of Bangladesh due to its dynamic natural environment. Climate related change represents potential additional stress on systems and the ecology in coastal zones is gradually being degraded. These bio-geophysical possessions will have subsequent effects on ecosystems and in time affect socio-economic systems in the coastal zone. Coastal zone have already been facing numerous climate change effects such as floods, salinity intrusion, river bank erosion, cold waves, cyclone, tornado, arsenic contamination in ground water and water logging; are gradually escalating by climate change and creating risks for the coastal people in Bangladesh. Research study is concerned with climate change related risks and hazards that affects the inhabitants of coastal Bangladesh. The study findings revealed that the climate change has affected the livelihood of coastal people in many sectors including scarcity of pure drinking water, extreme poverty, health problems, malnutrition, damage in crop cultivation, poultry, vegetables garden and fisheries. Elsewhere, it also created a state of unemployment among the peoples of coastal communities. As a result, the affected people are losing their means of livelihoods and forced to take several alternative ways to survive with the adverse impact of climate change associated disasters. Research paper reveals that the coastal community people try to solve their problems through embracing and exploring alternative employments. To reduce the impacts there are two options in the coastal zone of Bangladesh is that mitigation and adaptation. The country has very limited scope for mitigation cause of mitigation involves global efforts to execute and adaptation is more indigenous. As a result, effective adaptation policies and mitigation measures should be built-up and implemented to minimize climate related impacts on Bangladesh.
\end{abstract}

Keywords: Climatic Variability, Coastal Zone, Vulnerability, Impacts, Social Consequences, Economic Consequences, Alternative Livelihood 


\section{Introduction}

Bangladesh is a riverine country [1] [2]. In total 252 rivers are flowing from north to south of the country and flows of these rivers ultimately discharges into the Bay of Bengal [3]. The Ganges, the Brahmaputra and the Meghna are the major rivers of the country [4] [5]. These rivers together make Bangladesh - the largest delta of the world [6] [7]. Most of the people's life and livelihood of this country depend on this river net and its proper functions [8] [9]. Barisal division was established in 1 January, 1993. It has an area of 13295.55 sq. $\mathrm{km}$, is bounded by Dhaka division in the north, Bay of Bengal in the south, Chittagong Division in the east and Khulna Division in the west. It consists of six districts, 38 upazilas, 353 union parishads, 3159 mouzas, 12 municipalities, 25 wards and 4163 villages. The districts are Barisal, Jhalokati, Pirojpur, Bhola, Patuakhali and Barguna. Total Population is 7462644 of which male $50.67 \%$ and female $49.33 \%$. About $88.06 \%$ people are Muslim, Hindu $11.7 \%$, Christian $0.18 \%$ and others $0.06 \%$. Average literacy is $35.25 \%$. Main occupations of the people are agriculture (40.96\%), fishing (3.4\%), agricultural laborer (18\%), wage laborer $(4.59 \%)$, commerce $(11.92 \%)$, transport $(1.73 \%)$, construction (1.34\%), service $(7.39 \%)$ and others $(10.67 \%)$ [10]. Main crops are paddy, betel leaf, potato, sugarcane, oil seed, onion, garlic and vegetables. The area is famous for different seasonal fruits viz coconut, amra, guava, betel nut, banana [11]. A number of rivers, canals and creeks are spread over this division forming like a net. The area is vulnerable to cyclone, flood, drainage congestion, river erosion, and river sedimentation [12] [13]. Main rivers are Arial Kha, Bishkhali, Burishwar, Tentulia, Paira, Haringhata, Baleshwar, Kirtankhola, Katcha Lohalia and Agunmukha.

The cultural as well as livelihood pattern and economy of Barisal region is generally developed on the river eco-system [14]. But the situation has been changed a lot due to various natural and man-made reasons over the years [15]. The river flow of regional main rivers has decreased over decades, even more, some important rivers are already dead and some others are nearly dead [16]. A number of river connected khals and wetlands has now become history [17]. This region is also under serious threat of climate change consequences [18] [19]. Inbuilt environmental setting has already been changed which makes the people's life more vulnerable [20]. In addition to these, anthropogenic pressure on the natural resources added more concern on this environmental setting [21]. The factors causing problems of the rivers at Barisal and Patuakhali region are the results of cordon and commercial approaches followed in river water management inside and outside the country, respectively [22]. The waterway navigation is tremendously hampered, survival of people are at great risk due to flood, riverbank erosion, rising of river bed and changes in course of rivers [23]. These environmental issues have great implication on the livelihood and income of the people which ultimately increase the poverty level of marginal income groups [24]. The main objective of the program was to prepare a comprehensive exploratory report on the environmental issues associated vulnerability of people's livelihoods and probable way of solutions to protect the rivers and khals of the South Central region (Barisal and Patuakhali division) from environmental degradation in terms of navigability, river flow, navigation and water quality as well as to establish the rights of poor people dependent on the river eco-system and culture. The specific objectives are; a) To identify the present functional status of rivers, khals, wetlands and river training and management, b) To find out the reasons for environmental change and its impact, c) To find out the obstacles in water flow of rivers, khals and wetlands and suggest the probable mitigation measures, d) To determine the effect of unplanned construction of bridge, culvert and sluice gate and find out the remedial measure, e) To identify the risk and hazards of wastewater disposal in rivers, khals, wetlands along with their remedial measures, f) To dig out suggestion for improvement of the quality of water management and ensure efficient management.

\section{Contour of the Study Area}

\subsection{Study Area Coverage}

The study area covered the districts of Barisal Division, namely Barisal and Patuakhali. This study covers both environmental issues and water resources and its associated vulnerabilities of all the individual districts. In addition to the water resource problems, an effort was given to get an essence of public understanding on climate change events such as inconsistency of temperature, rainfall and sea level rise. District level workshops were held in district headquarters with the participation of relevant stakeholders including concern Government agencies and NGOs. The study also covered the root level peoples who have limited access in the decision making process such as day labors, fisherman, farmers, other marginal income groups through Focus Group Discussions (FGDs) to justify the outcome of the district level workshops. Some important water management problems identified during district level workshops were physical observed by the study team for indepth investigation. This report has been prepared base on the synthesized outcome of all these field activities.

\subsection{Frequency of Poverty in Barisal and Patuakhali District}

Rate of poverty in Barisal and Patuakhali districts at lower poverty line and upper poverty line is estimated by the Cost of Basic Needs Methods. We analyze only two years data 2000 and 2005 respectively. From this analyze we found that the incidence of poverty at lower poverty line in Barisal districts is increasing - it has increased in the year of 2005 compared to that in 2000 and in Patuakhali districts the upper poverty line is decreasing than 2000. (Source: Preliminary Report of Household Income and Expenditure Survey-2005, 
Bangladesh Bureau of Statistics, 2006.)

\subsection{Literacy Status and Educational Institutions by the Districts}

Literacy status and educational institutions in Barisal and Patuakhali districts are well. The average literacy rate in Barisal and Patuakhali districts are $42.9 \%$ and $36.4 \%$. In Barisal district the male and female literacy rate is $47.9 \%$ and $37.9 \%$. They have 54 Collage, 316 Secondary school, 33 junior schools, 1204 Govt. Primary school, 412 Non Govt. primary School, 698 Madrasa, 11 Kindergarten. In Patuakhali district the male and female literacy rate is $42.7 \%$ and $30 \%$. They have 28 Collage, 227 Secondary school, 37 junior schools, and 1150 Govt. Primary school.

\subsection{Distribution of Population by Main Occupation and the Districts}

The main occupation sectors of Barisal and Patuakhali district are agriculture, fishing, agricultural labor, wage labor, commerce, service, others. In Barisal district $35.28 \%$ people depends on agriculture, $3.45 \%$ on Fishing, $18.76 \%$ on Agricultural Labor and $12.57 \%$ on others. In Patuakhali district $45.84 \%$ depends on agriculture, $3.32 \%$ on Fishing, $16.72 \%$ on Agricultural Labor and $12.22 \%$ on others.

\subsection{Land Use by the Districts}

The land in barisal and patuakhali district are favorable for crop production. Barisal district have 178601 hectors of cultivable land, 5785 hectors fallow land, 37.68\% single crop land, 48.8\% double crop land and $13.52 \%$ triple crop land. Patuakhali district have 222899 hectors of cultivable land, 3694 hectors fallow land, 59.02\% single crop land, 37\% double crop land and $3.98 \%$ triple crop land.

\subsection{Communication Facilities by the Districts}

Communication networks in Barisal and Patuakhali district are more or less well. Barisal district have $363 \mathrm{~km}$ pucca road, $378 \mathrm{~km}$ semi pucca road, $3133 \mathrm{~km}$ mud road and 355 nautical miles waterways. Patuakhali district have $208 \mathrm{~km}$ pucca road, $208 \mathrm{~km}$ semi pucca road, $5341 \mathrm{~km}$ mud road and 224 nautical miles waterways.

\subsection{Health Centers by the Districts}

Medical facility of Barisal and Patuakhali district are not well. Barisal district have 1 general hospital, 11 upazila health complexes, 75 union healths and family welfare centre, 37 maternity and child care centre and 32 satellite clinics. Patuakhali district have 1 general hospital, 6 upazila health complexes, 6 union healths and family welfare centre, 40 maternity and child care centre and 19 satellite clinics.

\subsection{Justification of the Study}

Several districts of Bangladesh are vulnerable to natural calamities Barisal and Patuakhali region is one of them. Due to climate change environmental settings are changed and play a vital role to effects on lives and livelihoods of Southcentral coastal districts of Bangladesh. From this regard we notice that a research/study program needs to be undertaken to determine the intensity of problem and find out the remedial measures. So we select Barisal and Patuakhali as our study area and also select our research topics entitle as "Environmental Change and its impacts on lives and livelihoods of South-central coastal districts of Bangladesh".

\section{Materials and Methods}

Participatory approach has been followed in this study by ensuring the stakeholders participation in all stages of program. Both primary and secondary data has been collected from different sources to achieve the objectives of the study. Six district level workshops have been organized in all the districts of Barisal Division. Moreover, focus group discussion (FGD) has also been conducted with the occupational groups at different places of village level. The participants of the workshops included the Deputy Commissioners, LGI representatives (union \& upazila), upazila level government officials from BWDB, BIWTA, LGED, DPHE, DAE, DOF, DOL and representatives from different professional groups like teachers, lawyer, journalist, female social development workers and NGOs. The participants of the FGDs were farmers, fishermen, businessmen (small scale), agricultural, local affected peoples and non-agricultural laborers. We made a short visit to the River Research Institute (RRI), Faridpur to get expert views on the similar issues discussed in the workshops.

In addition to these, GIS maps were prepared for each districts and south central region showing the layers of BWDB projects, rivers network and settlements. These maps were used in the workshops to mark the geographical feature readily in the field. The output information of the workshops and FGDs were noted down in detail. The workshops participants also filled a set of questionnaires individually. The collective comments on the given checklist were recorded in the flip charts to get a participatory and agreed version of information from each district level workshops. Moreover, sound recorders were used to record the important comments of the local stakeholders as and when necessary. Photography of each activities and visited project sites were conducted using digital cameras. To see the workshops activities and stakeholder's responses, BWP professionals were requested to attend the workshop. The synthesized information of all districts will be compiled to produce a comprehensive exploratory report incorporating the major environmental issues with associated vulnerabilities to livelihoods and also the probable solutions of poverty alleviation. Comments and suggestion on the draft report will be incorporated in the final version of the report.

\section{Results and Discussions}

\subsection{Findings of the Study}

Major environmental problems of the study area as stated 
by the participants of the workshops are river banks erosion, siltation and accretion, internal navigation, salinity, surface water pollution, drinking water pollution and scarcity, construction of different structures across water bodies, declining aquatic resources, impact of changed natural environment on agriculture, problems of different water management projects and climate change. These environmental issues have great implication on the regional and local social dimensions which regulate the economic status of the people. These problems are evolved to some extent due to implementation of water management projects.

\subsection{Status of Water Resources}

Water resources of the study area are divided into Rivers, Khals and Beels. Life and livelihood of the peoples of this region depend on these rivers. Besides, a good number of existing minor rivers are also playing active roles in maintaining the natural ecosystem of the area. The status of major regional rivers seems to be in good condition but the scenario is changing due to a number of natural and anthropogenic factors. On the other hand, most of the internal canals and river are nearly dead. Some of the important small rivers like Gazipur, Halta (Barguna portion), Damadar, Dhansiri, Kalijira, Kumar, Mora Bishkhali are died already. Likewise, some important khals namely Shakhani Khal, Nijlatimara Khal, Kasi Chirani Khal, Koi-okhali Khal, Lawri Gazipuri Khal, are also died already and a noticeable number of Khals are about to die. The area has very small number of beels. From among those beels, Beel Dumuria, Beel Padho dubi, Beel Jasimabad, Phanakhali and Kumarkhali Mora Haor are mentionable. The status of these beels is good.

\subsection{Status of Water Management Projects}

Overall responsibility of water management of this area lays on Bangladesh Water Development Board (BWDB). A number of coastal polder projects were implemented by this organization to protect the localized area from saline water intrusion and flooding. The success stories of the projects have reflected in the previous decades through the highest paddy production of the country. Besides, BWDB has constructed an irrigation project in the greater Barisal region which is known as Barisal Irrigation Project (BIP) in eighties. The project has given positive result at the beginning but failed to serve long time due to lack of technical sustainability. However, the project is remodeling its irrigational schemes located at different districts of the study area. Some of those are already remodeled and working with pure satisfaction of the local stakeholders.

Local Government Engineering Department (LGED) is also involved in small scale water management projects locating within the BWDB project area. A number of projects have implemented in different districts of the Barisal region.

\subsection{The Reasons for Environmental Change and Its Impact}

The causes and factors associated with the environmental problems and their probable solutions are furnished below in the form of outputs, outcomes and impacts of the interventions implemented in planned or unplanned manner in the study area. 'Output' refers to the products, capital goods and services which result from a development intervention implemented in the study area; may also include changes resulting from the intervention which are relevant to the achievement of outcomes. 'Outcome' refers to the likely or achieved effects of an intervention's outputs. Outcomes are the observable behavioral, institutional and societal changes; and 'impact' refers to the positive and negative, primary and secondary long-term effects produced by a development intervention, directly or indirectly, intended or unintended. The detail findings of the study include the issues of status of water resources, reasons for environmental change and its impact and stakeholders suggested solutions in the following sections;

\subsubsection{Bank Erosion of Different Rivers and Khals}

The bank erosion is mainly associated with the rivers. The intensity of bank erosion is found severe to very severe in the study area. Bank erosion mainly caused by changes of courses of rivers/khals, changes of platform of major rivers, tidal influence, deforestation from the bank of rivers/khals, movement of heavy water vessels in rivers. Bank erosion causes number of negative impacts on the livelihood of the affected people. Local people lose their agricultural land, settlement and other valuable assets due to the bank erosion. People remarkably displaced from their land of origin and some of them literally became landless. The increasing number of landless people with low paid job or no job consequently increases the poverty level of the country over time.

\subsubsection{Siltation and Accretion of Land}

Unlike other rivers of the country siltation is one of the major problems of the rivers and khals of these coastal districts. The rivers of this region carry huge amount of sediment from upstream. Any disturbance in the rivers flow reduces its velocity and causes siltation. Increasing upstream sediment deposition during wet season, change of river flow direction, reduced river flow, riverbank erosion, construction of polder, sluice gate, bridge, culvert, road, decrease in flow velocity are accelerate the siltation and accretion of land. The intensity of siltation is high in the rivers of the study districts. Most of the minor rivers died due to high siltation. In addition to this, siltation causes obstacle in navigation; decreases navigability, water reservoir capacity of the water bodies, aquatic resources and capture fish production; increases level of water and transportation cost; causes frequent flooding; reduces availability of irrigation water; and increases water pollution due to drainage congestion.

\subsubsection{Loss of Navigability}

Loss of navigability (depth) is found very common in the rivers of study area. The main reason for loss of navigability are reduced upstream flow in the rivers which increase the rate of sedimentation in the river beds, restricted tidal fluctuation in the khals by constructing polders and sluice 
gates, reduction of flow velocity, inadequate opening of existing sluice gates, excessive river erosion and sedimentation. Average rivers depth of the study districts are reduced over time and remain in bad condition. The consequences of loss of navigability are increase in tidal flooding, decrease in aquatic resources, capture fish production, hamper navigation, shortage of irrigation water, water level rising, and degradation of ecosystems.

\subsubsection{Salinity Intrusion}

Unlike other coastal districts salinity intrusion in the rivers and khals is not so severe. Local people reported that the status salinity intrusion of the rivers is reducing in recent years. Sea level rise, change of river flow direction, reduced upstream flow which increases the rate of salinity intrusion. The impacts of salinity intrusion are decrease soil fertility due to application of higher doze of zinc fertilizer in the agricultural land, decrease fresh water fishes, reduce agriculture production, hamper irrigation of boro crops during dry season months, mangrove forest instigation instead of cultivation, and increase soil salinity.

\subsubsection{Water Pollution (Rivers/Khals)}

Water pollution is mainly restricted in the rivers situated surroundings of towns and industrial area due to waste disposal and sewerage discharge. Excessive and unplanned use of chemical fertilizer and pesticides in the agricultural land are also responsible. Most of the hanging latrine were removed which also increased pollution of the surface water of the study area. However, surface water pollution is still not so severe. Surface water pollution causes bad odor, outbreak of fish diseases, death of other aquatic resources, deteriorate water quality, drinking water scarcity and also increase water borne diseases.

\subsubsection{Construction of Unplanned Water Management Structures}

Unplanned water management structures constructed in different locations of the study area resulted multidimensional problems. In most cases the structures are malfunctioning. Inactive and corrupted local water management committee, lack of inter-departmental integration, political influence, reluctance of project planners in considering environmental issues during project planning and implementation, lack of local stakeholders involvement during project planning and implementation. Major impacts of these unplanned structures are decline of aquatic resources, creation of drainage congestion, river/khal siltation, irrigation water scarcity, obstacle in fish migration, and loss of aquatic resources and fish habitat.

\subsubsection{Declining Aquatic Resources}

The aquatic resources of the study districts are declining alarmingly. Contamination of river/khals water by chemical fertilizer and pesticides residues of agricultural land, obstacle in biological process of aquatic animals by constructing unplanned structures, water pollution, loss of navigability, and indiscriminate resource collection are the main reason of declining aquatic resources. The impacts of declining aquatic resources are - decrease capture fish production, locally extinction of indigenous fish species and water bird, increase unemployment, increase out migration.

\subsection{Changes of Natural Environment and Its Impacts on Agriculture}

The changes in the components of ecosystems limit the agriculture production in many ways. Among others agricultural production hampered due to climate change factors, malfunctioning of water management structures, absence of adaptive cropping pattern, unplanned cultivation, lack of improved agriculture technology, optimum utilization of agricultural land, scarcity of irrigational water, reduce siltation rate on agriculture land due to polders, and reduce soil fertility due to excessive use of chemical fertilizer and pesticides. On the contrary, paddy production had been increased due to introduction of high yielding varieties (HYV) and access to HYV and use of chemical fertilizers. The cost of per unit paddy production had been increased tremendously. Marginal farmers could not effort with the increased production cost and changed their occupation. On the other hand, production of other Rabi crops had been decreased in the study area. The income of agriculture dependent community had decreased. The number of marginal farmers had increased as well as increased the poverty level. All these make the life of poor people more vulnerable.

\subsubsection{Temperature Increasing}

Deforestation, Decrease of rainfall, Air pollution, Green House Effect, Increase population, Drought is accelerating the problems. Impacts of temperature increasing are sea level rise, reduce crop production, rainfall decreasing, dehydration problems and many more.

\subsubsection{Rainfall Decreasing}

Rainfall decreasing are also problems in the south coastal districts. Temperature increasing, deforestation, climate change, increase of carbon content in air, low down moisture are responsible for rainfall decreasing. Impacts of rainfall decreasing are reducing crop production, increase peast attacked respectively.

\subsubsection{Changes in the Society}

The investigation reveals that the above mentioned environmental changes have negatively impacted on the socio-economic parameters such as - increase occupational change, reduce employment opportunity, reduce income, loss of valuable wealth, increase health problems, increase rate of out migration, increase social conflict and overall increase poverty. The consequences of these negative changes ultimately increase the pressure on the natural resources.

\subsection{Status of Climate Change}

People's understanding and experiences on the climate change in terms of changes in temperature, rainfall pattern 
and water level. Local people are aware of and experienced with the climate change factors. They reported that temperature increased in the summer season and duration of winter decreased. Winter is not so cold and remains foggy. The frequency of winter rainfall is increases and thus the pattern of rainfall changes. Huge rainfall within a short period is very common now a day. On the other hand, duration of drought period increases. Water level of rivers increases. But the reason behind this is not clear. According to some people water level is increasing due to heavy siltation and poor water storage capacity of rivers. People are not adapted to these changes. They, therefore, face problem of unusual flood, storm, etc. They are yet to stand in copping this changed situation.

\section{Conclusion and Recommendations}

The investigation on "Environmental Change and its Impact on Livelihood" reveals the problems, associated causes and impact and probable solutions of coastal districts of Barisal and Patuakhali region. The perceived solutions of the problems stated by the participants of the workshops and FGDs are described. Execution of the solutions of their problems only can alleviate the poverty from the study area and thus the increasing tendency of incidence of poverty in Barisal and Patuakhali division can be stopped. The standard of life of people will be enhanced. People, therefore, suggest recommendations on their felt needs and aspirations.

From FGD, PRA, RRA suggested solutions made by the stakeholders are summarized below: Maintaining of sufficient river channel depth, block pitching and training works, river channel should be clear from submerged bar, river dredging and khal re excavation river bank pilling, construction of bank protection wall, bank protection with block, sand bag. Construction of spar to change flow direction, increase vent size of existing sluice gate, remove unplanned structure of the khals, distribute newly develop char/land to original land owner, restrict unplanned settlement, remove submerged bar using dredger machine. Afforestation in the newly developed chars, restrict waste dumping into the river/khals situated along the towns.

Allow open sand collection from river bed, construct embankment and sluice gates to protect salinity, discharge sewerage water after proper treatment, establish effluent treatment plant (ETP) for maintaining water pollution, discharge sewerage water after proper treatment, restrict solid waste dumping and sewerage discharge in the water bodies, consider environmental issues during project planning, ensure stakeholders participation in project planning and implementation. Avoid political biasness in selection of project locations, long term planning, follow proper design during implementation, avoid partial implementation of the project, prohibit indiscriminate fishing, increase use of organic manure, awareness raising among the local farmers to use bio-fertilizer and bio-pesticides. Improve irrigation water retention facility, strengthen agriculture extension services, consider environmental issues in project planning, and ensure involvement local stakeholders during project implementation

Provide training on the alternative income generating activities (AIGA), integrated planning for optimum resources management, introduce modern and sustainable technologies to increase cropping intensity. Ensure availability of inputs like seeds, irrigation, bio-manure, fertilizer and pesticide on time for crop production. Introduce adaptive cropping pattern in the changed climate scenario, introduce co-operative farming, implement of previous study findings. Protect over exploitation of aquatic resources, construct feeder canals for enhance water reservoir capacity in the cropland, proper monitoring by BWDB. Establish branch office of river research institute (RRI), special tree plantation along riverbank, erosion prediction and forecast by radio and $\mathrm{TV}$, co-ordination among government agencies (BWDB, LGED, DAE, RHD, BADC and Union Parishad) during project planning.

\section{References}

[1] Al-Farouq, A., \& Huq, S. (1996). Adaptation to climate change in the coastal resources sector of Bangladesh: Some issues and problems. In Adapting to climate change (pp. 335342). Springer New York.

[2] Rashid, A. M. (2009). Climate change vulnerability in Bangladesh. Bangladesh: Dustha Shastha Kendra (DSK).

[3] Afroz, R., \& Rahman, M. A. (2013). Transboundary river water for Ganges and Teesta rivers in Bangladesh: an assessment. Global Science and Technology Journal, 1 (1), $100-111$.

[4] Saha, C. K. (2015). Dynamics of disaster-induced risk in southwestern coastal Bangladesh: an analysis on tropical Cyclone Aila 2009. Natural Hazards, 75 (1), 727-754.

[5] Datta, D. K., \& Subramanian, V. (1998). Distribution and fractionation of heavy metals in the surface sediments of the Ganges-Brahmaputra-Meghna river system in the Bengal basin. Environmental Geology, 36 (1-2), 93-101.

[6] Minar, M. H., Hossain, B., \& Shamsuddin, M. D. (2013). Climate change and coastal zone of Bangladesh: vulnerability, resilience and adaptability. Middle-East Journal of Scientific Research, 13 (1), 114-120.

[7] Akter, J., Sarker, M. H., Popescu, I., \& Roelvink, D. (2015). Evolution of the Bengal Delta and Its Prevailing Processes. Journal of Coastal Research.

[8] Pender, J. S. (2008). What is Climate Change?: And how it Will Effect Bangladesh. Dhaka: Church of Bangladesh social development programme.

[9] Uddin, B., Hasan, I., \& Islam, G. R. S. (2018). Coastal livelihood vulnerability rural farmers to climate change district of Bangladesh.

[10] Nasreen, M., \& Azad, M. A. K. Climate Change and Livelihood in Bangladesh: Experiences of people living in coastal regions.

[11] Shamsuddoha, M., \& Chowdhury, R. K. (2007). Climate change impact and disaster vulnerabilities in the coastal areas of Bangladesh. COAST Trust, Dhaka. 
[12] Alauddin, S. M., \& Rahman, K. F. (2013). Vulnerability to climate change and adaptation practices in Bangladesh. $\mathrm{J}$ SUB, 4 (2), 25-42.

[13] Demirkesen, A. C., \& Evrendilek, F. (2017). Compositing climate change vulnerability of a Mediterranean region using spatiotemporally dynamic proxies for ecological and socioeconomic impacts and stabilities. Environmental monitoring and assessment, 189 (1), 29.

[14] Bhuiyan, M. J. A. N., \& Dutta, D. (2012). Analysis of flood vulnerability and assessment of the impacts in coastal zones of Bangladesh due to potential sea-level rise. Natural hazards, 61 (2), 729-743.

[15] Akhtar, P., Ahmed, Y., Islam, F., Alam, K., Mary, M., Islam, M. Z., \& Yaakob, Z. (2016). Efficiency of Effluent Treatment Plants and Threat to Human Health and Aquatic Environment in Bangladesh. Asian Journal of Chemistry, 28 (1), 60.

[16] Kundzewicz, Z. W., Mata, L. J., Arnell, N. W., Döll, P., Jimenez, B., Miller, K.,... \& Shiklomanov, I. (2008). The implications of projected climate change for freshwater resources and their management.

[17] Bunn, S. E., \& Arthington, A. H. (2002). Basic principles and ecological consequences of altered flow regimes for aquatic biodiversity. Environmental management, 30 (4), 492-507.
[18] Ahmed, A. U. (2006). Bangladesh climate change impacts and vulnerability.

[19] Mathew, L. M., \& Akter, S. (2017). Loss and damage associated with climate change impacts. Handbook of climate change mitigation and adaptation, 17-45.

[20] Lasco, R. D., Habito, C. M. D., Delfino, R. J. P., Pulhin, F. B., \& Concepcion, R. N. (2011). Climate change adaptation for smallholder farmers in Southeast Asia.

[21] Ali, A. (1999). Climate change impacts and adaptation assessment in Bangladesh. Climate research, 12 (2-3), 109116.

[22] Amir, K. I., \& Ahmed, T. (2013). Climate Change and Its Impact on Food Security in Bangladesh: A Case Study on Kalapara, Patuakhali. Bangladesh. J Earth Sci Clim Change, 4 (155), 2.

[23] Minar, M. H., Hossain, B., \& Shamsuddin, M. D. (2013) Climate change and coastal zone of Bangladesh: vulnerability, resilience and adaptability. Middle-East Journal of Scientific Research, 13 (1), 114-120.

[24] Iftekhar, M. S. (2006, August). Conservation and management of the Bangladesh coastal ecosystem: overview of an integrated approach. In Natural Resources Forum (Vol. 30, No. 3, pp. 230-237). Blackwell Publishing Ltd. 